\title{
O DIAGNÓSTICO FONOAUDIOLÓGICO NA PARALISIA CEREBRAL: 0 SUJEITO ENTRE A FALA E A ESCUTA
}

Giuliana Bonucci Castellano e Regina Maria Ayres de Camargo Freire

\author{
Giuliana Bonucci \\ Castellano \\ Fonoaudióloga, \\ especialista em \\ Linguagem e mestre \\ em Fonoaudiologia \\ pela Pontifícia \\ Universidade \\ Católica de São \\ Paulo; pesquisadora \\ da linha Linguagem \\ e Subjetividade \\ do Programa de \\ Estudos Pós- \\ Graduados em \\ Fonoaudiologia da \\ PUC-SP.
}

Regina Maria Ayres de Camargo Freire Fonoaudióloga, mestre em Linguística Aplicada e Doutora em Psicologia da Educação pela Pontifícia Universidade Católica de São Paulo; pósdoutorado pela Universidade de São Paulo; professora. titular do curso de graduação e pós-graduação em Fonoaudiologia da PUC-SP
RESUMO: Este artigo destaca a clínica fonoaudiológica como espaço para a escuta do corpo (falante) de portadores de paralisia cerebral e objetiva estudar o caso clínico de uma adolescente para estabelecer o diagnóstico diferencial próprio ao campo fonoaudiológico. Dados das investigações anamnéstica e armada, das entrevistas preliminares e de fragmentos das sessões de terapia fonoaudiológica, durante as quais se utilizou um diário e uma prancha de Comunicação Suplementar e/ou Alternativa, analisados com base no Modelo de Organização dos Sintomas de Linguagem dão sustentação ao diagnóstico fonoaudiológico, que, em sendo diferencial, indica a direção do tratamento.

Palavras-chave: Paralisia cerebral, sujeito, fala, linguagem, fonoaudiologia.

ABSTRACT: The speech and language diagnosis in cerebral palsy: the subject between speech and listening. This article highlights the speech and language therapy as a space for listening to the (talking) body of subjects with cerebral palsy and aims to study the case of a teenager in order to establish differential diagnosis, specific to the speech and language therapy field. Data from anamnestic and armed investigations, from preliminary interviews and fragments of speech and language therapy sessions, in which a diary and a board of Supplementary and/or Alternative Communication were used, were analyzed based on the Language Symptoms Organization Model, which gives sustainability to the speech and language diagnosis that, being differential, indicates the direction of treatment. Keywords: Cerebral palsy, subject, speech, language, speechlanguage clinic. 


\section{INTRODUÇÃO}

A Organização Mundial de Saúde descreve a paralisia cerebral (PC) como um grupo heterogêneo de transtornos motores não progressivos causados por lesões cerebrais crônicas, originadas desde os períodos pré-natais, perinatal ou pós-natal até os primeiros 5 anos de vida. Essas lesões cerebrais imprimem marcas no corpo que afetam, principalmente a condição motora dos portadores de PC e/ou, em alguns casos, a fala e a relação com o outro. Assim, alguns estarão "impossibilitados organicamente de falar de forma articulada” (CHUN, 2003, p.54), mas não de comunicar-se: "mas como a língua, à qual a fala está relacionada, não é afetada por ser de outra ordem que a do corpo orgânico, pode-se afirmar que os portadores de PC apresentam fala, ainda que por outras modalidades" (CASTELLANO, 2010, p.1).

A clínica fonoaudiológica aqui representada, sob os efeitos de sua interlocução com a psicanálise lacaniana, abre espaço para a escuta do corpo (falante) ${ }^{1}$ desses indivíduos, interpretando gestos, traços ou designações como forma alternativa de fala e, assim, apesar das marcas motoras irreversíveis, dá voz aos portadores de PC pela fala do outro. Desta forma, a fala do PC endereçada ao fonoaudiólogo configura a demanda em ser escutado, reconhecido, significado e interpretado em suas expressões faciais, corporais, sonoras e em seu silêncio, uma vez que este também é constitutivo da linguagem. Desse modo:

"Nesta clínica fonoaudiológica que atribui ao sujeito um lugar de inscrição que emana da interação discursiva com o Outro, ${ }^{2}$ o diálogo é compreendido como essência do processo terapêutico, e nela o fonoaudiólogo passa a ser a instância promotora de uma relação outra com o Outro. É neste sentido que a relação dialógica para esses sujeitos pode ser sustentada por outros meios que a fala (em sua materialidade sonora), como é o caso da Comunicação Suplementar e/ou Alternativa (CSA).” (CASTELLANO, 2010, p.5)

É sobre esse corpo falado - por isso, falante - que iremos nos deter aqui, dado ser esta clínica atravessada pela interrogação sobre o que a fala que faz sintoma evoca. Neste caso, o fonoaudiólogo opera como intérprete do funcio-

\footnotetext{
${ }^{1}$ Ainda que o sujeito não tenha a fala oralmente articulada, o seu corpo se comunica por meio de gestos que, interpretados pelo outro, ganham o estatuto de fala. Daí ser, o corpo, falante, de forma que este e o sujeito falante são, aqui, entendidos como homólogos. A noção de sujeito que consideraremos aqui decorre da nossa aproximação com a psicanálise lacaniana e refere-se ao sujeito constituído pela linguagem e na relação com o Outro, sendo dotado de inconsciente e como efeito do significante.

${ }^{2}$ Outro grafado em maiúscula, deve ser entendido ao longo deste trabalho, tal como Lacan o define no Seminário 3, como "o lugar de onde o sujeito recebe a sua mensagem invertida. (...)" (LACAN, 1955-56/2002, p.47).
} 
namento da linguagem do outro. Trata-se de uma terapêutica em que ambos — fonoaudiólogo e sujeito — situam-se em uma cadeia intersubjetiva pela qual são operadas transformações na linguagem daquele com PC. No entanto, para que esses princípios possam ser eficazes no atendimento clínico, faz-se urgente delinear uma forma, ainda que preliminar, de diagnóstico diferencial, para que este sustente a terapêutica.

Portanto, o objetivo deste trabalho é trazer um estudo de caso clínico de uma adolescente com PC, com graves sintomas no corpo que impedem sua fala oral articulada, a fim de traçar as diretrizes para o diagnóstico preliminar das perturbações de linguagem e estabelecer uma direção para o tratamento. Estas diretrizes serão sustentadas pelo Modelo de Organização dos Sintomas de Linguagem (GOUVÊA, FREIRE e DUNKER, 2011) que, assentado sobre premissas advindas da linguagem e da psicanálise, explica a estrutura e o funcionamento dos sintomas de linguagem, articulados à estrutura clínica fonoaudiológica.

\section{O MODELO DE ORGANIZAÇÃO DOS SINTOMAS DE LINGUAGEM NA FONOAUDIOLOGIA}

A afirmação abaixo sustenta este estudo de caso clínico:

“...os sintomas de linguagem, na Fonoaudiologia, pertencem a uma estrutura complexa de múltiplos estratos e interestratos sucessivos e superpostos que operam por contradição, oposição e diferença, [estrutura que] contém os intervalos espaciais, temporais e lógicos da linguagem, formando uma espécie de grade topológica dividida esquematicamente nos eixos horizontais - escrita, língua e fala - em relação aos eixos verticais - sujeito, Outro, metáfora e metonímia.” (GOUVÊA, FREIRE e DUNKER, 2011, p.17, grifos nossos)

A noção de estrato indica as diferentes superfícies da linguagem — escrita, língua e fala - , nas quais os sintomas se formam e que operam de maneira simultânea, e não hierárquica. A acepção de contradição estaria ligada ao paradoxo temporal entre instâncias distintas, por exemplo, no caso da diacronia e da sincronia, em que "as relações lógicas e psicológicas que unem os termos coexistentes", sofrem um espaço temporal, de modo que o tempo de transformação sincrônico se dá por combinações sucessivas e a diacronia diz respeito aos "termos sucessivos que se substituem uns aos outros no tempo" (SAUSSURE, 1916/2006, p.163). Neste sentido, “A linguagem é um sistema de valor, que pode ser comparado a um jogo de xadrez", sendo que as propriedades de seus valores estão simultaneamente submetidas a uma relação entre coisas dessemelhantes e semelhantes. Deste modo, o sistema de valor está fundamentado na diferença, que demanda uma cadeia na qual "um termo só adquire seu valor 
porque se opõe ao que o precede ou ao que o segue, ou a ambos" (SAUSSURE, 1916/2006, p.142). A diferença implica negação, relação e oposição. No que se refere à relação: "numa linguagem, os signos adquirem valor por suas relações uns com os outros" (LACAN, 1966/1998, p.298), como no caso do fonema. Já a oposição "envolve uma escolha entre dois termos de uma oposição que apresenta uma propriedade específica diferencial em divergência com as propriedades de todas as demais oposições" (JAKOBSON, 1955/1975, p.66) — por exemplo, o contraste entre vogais e consoantes. Por fim, a negação ou a sanção "é a barreira que resiste à significação" (GOUVÊA, FREIRE e DUNKER, 2011). Ou seja, negação e recusa ou do sujeito ou do significante entram no jogo da língua pelos efeitos operados concomitantemente pelo sujeito, pela sanção e pelos processos metafóricos e metonímicos que engendram os modos de reconhecimento e negação dos sintomas de linguagem.

O Modelo de Organização dos Sintomas de Linguagem afirma que cada estrato representaria um tipo de estrutura que comporta sistemas de valores distintos, isto é, são compostos por princípios distintos e reduzidos a uma única hipótese: a de que são efeitos do falante e da sanção do Outro.

A sanção é o estabelecimento das leis da linguagem entre os falantes, que se dá a ver a partir dos seus efeitos retroativos: quando alguém sanciona a fala de outrem, produz simultaneamente efeitos na fala, na língua e na escrita, no sujeito, no Outro e na relação intersubjetiva. Assim, “sancionar é, ao mesmo tempo, validar ou vetar uma fala e reconhecer ou desconhecer um falante, de modo que uma pluralidade de efeitos pode ser decorrente de um mesmo ato" (GOUVÊA, FREIRE e DUNKER, 2011, p.22).

Segundo os autores, há três modalidades de sanção para se reconhecer ou negar o uso de fala: a sanção ao ato, ao sujeito e sobre a lei. A sanção ao ato é definida pelas operações fonoaudiológicas que permitem, interditam, prescrevem ou facultam o uso da linguagem. A sanção ao sujeito implica os mecanismos de tradução - passagem de um significante para outro significante (sistema de significantes); de transcrição — passagem de um signo para outro (sistema de signos); e de transliteração — passagem de um sistema de escrita para outro (sistema de traços). No caso da sanção sobre a lei, teríamos: a sanção da lei como assunção da língua pelo falante no funcionamento da linguagem; sanção à lei, como submissão do falante às regras de estrutura da linguagem; e sanção pela lei, como ato de reconhecimento da fala, da língua e da linguagem pelo outro, pois a sanção do Outro "é... o significante que funda o significante, como o significante que instaura a legitimidade da lei ou do código" (LACAN, 195758/1999, p.156-157). 
Para situar o leitor, retomaremos os três estratos horizontais da grade topológica dos sintomas de linguagem - a escrita, a língua e a fala e suas relações com os eixos verticais - o sujeito, o Outro e a metáfora e a metonímia.

O estrato da escrita se caracteriza por um sistema de traços, ou seja, "pela lógica de inscrição da letra significante no corpo e não deve ser entendido apenas como a redação sobre o papel ou suporte assemelhado" (GOUVÊA, FREIRE e DUNKER, 2011, p.17). Assim, o traço é o suporte material do significante, sendo a primeira marca diferencial recebida pelo sujeito. No Seminário "A identificação", LACAN (1961-62/1996) afirma que o significante participa da leitura do traço, mas não coincide com ele, e então enuncia que os traços imprimem continuidade, rasura e apagamento, ou seja: para que o traço possa encadear-se com outro, precisa perder algo de si, de seu traçado, para que possa vir a se tornar significante. Além disso, refere que o traço é anterior à entrada do significante e condição para que (o traço) se transforme em significante, faça cadeia e que algo nele se apague. Já a rasura do traço pode ser lida como mancha, sombra ou como traço que faz litoral. Fato semelhante parece ocorrer como efeito da sanção sobre o traço na formação dos sintomas de linguagem. O exemplo aqui tomado será o efeito de alienação à sanção da fala do outro, de modo que o sujeito seja mais falado pelo outro, uma vez que a alienação é o "primeiro acasalamento significante que nos permite conceber que o sujeito aparece primeiro no $\mathrm{Ou}$ tro" (LACAN, 1964/1998, p.207). Os gradientes vocais e corporais, tais como a sucessão sonora, a designação ostensiva, o riso, o silêncio, os murmúrios, os sons, os resmungos, deixam rastros sobre a falta do significante e são marcados como traços; deste modo, sendo o corpo sobredeterminado pela estrutura da escrita, somos levados a pensar que é também articulado pela sua relação com a sanção do Outro, de forma que este corpo é mais falado e olhado pelo Outro.

O estrato da língua se caracteriza pela propriedade do código. A língua é um sistema que conhece apenas a sua ordem própria na qual se encontram as leis e um funcionamento que estão na dependência da relação entre significante e significado. A natureza do signo fundamenta-se na unidade linguística entre a associação de um termo a uma coisa e designa o signo linguístico como uma entidade psíquica, pois é abstrato, e tem duas faces: significado (conceito) e significante (imagem acústica) (SAUSSURE, 1916/2006).

No que se refere à noção de significado, Lacan afasta-se de Saussure e nos diz que este não tem nada a ver com os ouvidos, mas somente com a leitura com a leitura do que se ouve de significante. "O significado não é aquilo que se ouve, o que se ouve é o significante. O significado é efeito do significante" (LACAN, 1971/2003, p.74). "O significante é o que representa um sujeito para outro significante" (LACAN, 1969-70/1992, p.27), sendo este submetido às duas funções: a primeira, de ser composto por elementos articulados por oposição, 
negação e diferença; e a segunda, de se compor segundo “anéis cujo colar se fecha no anel de outro colar feito de anéis" (LACAN, 1966/1998, p.505). A barra que separa o significante do significado é a "barreira que resiste a significação" (LACAN, 1966/1998, p.506), ou seja, é a negação ou a sanção. Deste modo, a primeira função do significante é a metonímia, e a segunda é a metáfora. O polo da metáfora refere-se à seleção entre termos alternativos que implica a possibilidade de substituir um pelo outro, equivalente ao primeiro em um aspecto e diferente em outro; já o segundo polo, da metonímia, possibilita a combinação com outros signos (JAKOBSON, 1969/2001). Este estrato caracteriza-se pelo efeito refratário da sanção sobre o significante e o sujeito, cujos sintomas de linguagem formam-se pelo movimento de separação da fala do sujeito e da fala do outro ou pela divisão do sujeito e o do significante. O efeito da sanção do Outro ocorre pelo que os autores (GOUVÊA, FREIRE e DUNKER, 2011) denominam de "negação recíproca”, ou seja, nega-se o sujeito que fala e os significantes que foram falados: "negativismo e recusa ou do sujeito ou do significante entram no jogo da língua pelos efeitos dos arranjos operados simultaneamente pelo sujeito, pela sanção e pelos processos metafóricos e metonímicos que engendram os modos de reconhecimento e negação dos sintomas de linguagem” (GOUVÊA, 2007, p.7).

Ou ainda, desse modo, a sanção operada no estrato da língua se dá a partir de uma prática fonoaudiológica que pressupõe modificar a fala pela alternatividade e interrogatividade, ou seja, ao sancionar o reconhecimento da língua não reconhece a mensagem ou sanciona-se a mensagem como mensagem, não o código.

Por fim, o estrato da fala se configura pela lógica dialogal. Em primeiro lugar, porque "falar não é simplesmente ser o agente ou usuário de uma língua, falar é também ser autor. Falar é aceitar e modificar uma regra, realizar o universal da linguagem no singular de um sujeito" (GOUVÊA, FREIRE e DUNKER, 2011, p.12), mas também porque a fala comporta uma dimensão paradoxal, ou seja, como ato temporal, como acontecimento individual da fala, como fala de alguém endereçada ao Outro, pois "não há fala sem resposta, mesmo que depare apenas com o silêncio, desde que ela tenha um ouvinte" (LACAN, 1966/1998, p.249). Deste modo, a estrutura da fala pode ser explicada desde o lugar que "o sujeito recebe sua mensagem do outro sob uma forma invertida..." (idem, 1955$56 / 2002$, p.47). Isto porque a fala teria a propriedade de fazer ouvir o que ela não diz. Deste modo, a escuta vai para além do discurso, e, assim, "o Outro é, portanto, o lugar onde se constitui o eu que fala com aquele que ouve" (LACAN, 1966/1998, p.308). A sanção operada sobre este estrato produz efeitos de reversibilidade entre quem fala e quem escuta e os seus efeitos envolvem a sanção como reconhecimento no sujeito e no significante. A reformulação e a ressignificação da cadeia de fala estão subordinadas ao funcionamento da linguagem e geram efeitos no estrato da fala. “A negação por conservação é característica 
deste eixo.... é o caso mais explícito de incidência da sanção metalinguística" (GOUVÊA, FREIRE e DUNKER, 2011, p.18).

Parafraseando os autores acima, a lógica da grade topológica dos sintomas de linguagem reside no fato de que tais sintomas, ao se apresentarem em um estrato, estariam conectados a um problema estrutural de outro estrato - por exemplo, o efeito da alienação da sanção do Outro, como a repetição da própria fala, e o efeito da sanção como negativismo para o significante, corresponderiam a um problema estrutural no estrato da fala. Trilhados estes caminhos, os autores sugerem uma regra de ação: que a terapêutica não incida sobre os sintomas no mesmo estrato discursivo do sujeito. Assim, o tipo de sanção que deveria estar em vigor no exemplo acima seria o de sancionar a fala do sujeito por operação tradutiva, sancionar o ato como permissividade para o uso da fala e sancionar pela lei o reconhecimento do sujeito e do significante.

Antes de finalizar esta seção, é importante esclarecer brevemente que a teoria sobre a mudança de infans a sujeito falante (DE LEMOS, 1955), tem forte influência sobre o Modelo de Organização dos Sintomas de Linguagem. De Lemos (2002) propõe três momentos ou posições predominantes nesse processo, conhecido como Curva-em-U. No primeiro tempo, a fala da criança, estando circunscrita à fala do Outro, incorporaria fragmentos metonímicos da fala do adulto, denominada posição do acerto, uma vez que a criança é falada pelo outro. Já no segundo tempo, a fala da criança estaria submetida ao movimento da língua e se caracterizaria pelos erros e pela impermeabilidade a sua correção pelo adulto, momento marcado pelo fato de que a criança não conseguiria escutar a diferença entre o que fala e o que o outro diz. Por fim, no terceiro tempo, haveria o deslocamento do falante em relação à própria fala, à fala do outro e à língua, o que permitiria a reformulação e a escuta para a própria fala e para a fala do outro, sendo marcada como posição do acerto.

Podemos inferir, no entanto, que desta teoria sobre a fala da criança escaparia a explicação de como os sintomas de linguagem são formados. Além disso, parece-nos que o Modelo de Organização dos Sintomas de Linguagem, pela sanção sobre o ato, o sujeito e a lei, permitiria não só explicar a constituição dos sintomas de linguagem, como a sua reversão, indo do patológico ao normal. Ainda teríamos outra diferença, que seria a noção de traço como anterior à incorporação de fragmentos metonímicos, uma vez que o traço antecede o significante; assim, haveria ao menos outro tempo no percurso do infans a sujeito falante, que seria o momento em que não há significante ou fragmentos metonímicos, apenas traços.

O Modelo de Organização dos Sintomas de Linguagem (GOUVÊA, FREIRE e DUNKER, 2011) parece corroborar a noção de estrutura clínica fonoaudiológica, pois permitiria analisar os sintomas de linguagem e construir uma semiologia 
ancorada em elementos internos à linguagem; inferir hipóteses etiológicas entre os estratos da linguagem, próprias à clínica fonoaudiológica; fazer diagnósticos diferenciais como uma forma singular da maneira pela qual o sujeito lida com a própria linguagem; e, a partir dessas correlações, direcionar a terapêutica fonoaudiológica com manejos sobre a escrita, a língua e a fala, respeitando-se os princípios de homogeneidade e covariância entre os elementos clínicos, como os presentes na estrutura da clínica clássica em relação a uma estrutura de linguagem.

\section{APRESENTAÇÃO DO CASO CLÍNICO}

Este estudo de caso foi realizado em uma instituição do estado de São Paulo, sem fins lucrativos, que atende especificamente e de forma multidisciplinar portadores de PC. Nesta seção acompanharemos a avaliação diagnóstica de Sabrina (pseudônimo do sujeito da pesquisa), a partir dos dados do seu prontuário e das entrevistas preliminares. Desses dados, apresentaremos os fragmentos considerados relevantes para este estudo.

Pela forte aproximação da clínica médica na fonoaudiologia, encontramos em seu prontuário apenas dados referentes às investigações anamnéstica e armada, que fazem parte da avaliação diagnóstica médica (DOR, 1997). Outro tipo de aproximação utilizada no campo fonoaudiológico são as entrevistas preliminares (DOR, 1997), que advêm da clínica psicanalítica de orientação lacaniana e se assentam no endereçamento da demanda ao analista a fim de estabelecer o diagnóstico por meio da sua escuta ao dito pelo sujeito na transferência. Dessa forma, não é possível prever o tempo que isso demandará, pois na diagnóstica do campo psicopatológico "é quase impossível, determinar com segurança uma avaliação diagnóstica sem o apoio de um certo tempo de análise". Assim, o tempo é "necessário a observação" e este "é o tempo dedicado ao que habitualmente chamamos de 'entrevista preliminar" (DOR, 1997, p.15-16).

Para facilitar a leitura, os fragmentos terapêuticos foram transcritos em ortografia regular, nos quais os diacríticos $\rightarrow \mathrm{e} \uparrow$ indicam, respectivamente, os gradientes de entoação linear e ascendente e os parênteses ( ) contêm a descrição dos movimentos corporais e do contexto extralinguístico. A sucessão sonora prolongada foi marcada por :: e o sublinhado indica falas simultâneas dos interlocutores. As falas da fonoaudióloga e do sujeito foram grafadas em negrito e identificadas respectivamente, pelas maiúsculas F. para fonoaudióloga e $\mathbf{S}$. para o sujeito. Os turnos de fala foram marcados por numerais arábicos sequenciais para facilitar a leitura das análises e, por fim, a leitura do diário pela fonoaudióloga estará marcada com aspas e em itálico. 


\section{Investigação anamnéstica}

De acordo com os dados do seu prontuário, Sabrina obteve diagnóstico médico de paralisia cerebral espástica quadriparética, decorrente de um quadro de anoxia perinatal com um ano e dois meses de idade.

Aos 6 anos de idade ingressou na instituição onde se realizou este estudo, para acompanhamento multidisciplinar nas áreas de Fisioterapia, Fonoaudiologia, Psicologia, Terapia Ocupacional e Pedagogia. Está em atendimento fonoaudiológico há 13 anos nesta instituição.

A avaliação fonoaudiológica descreve hipotonia dos órgãos fonoarticulatórios, dificuldade no controle salivar, incoordenação de mastigação e deglutição e presença de sucessão sonora ééé... para responder à fala do outro.

A terapêutica fonoaudiológica esteve centrada no desenvolvimento da motricidade orofacial, especificamente na função de mastigação e deglutição, para a diminuição da sialorreia e lateralização da língua. A prancha de CSA, contendo alguns símbolos isolados referentes a atividades de vida diária e necessidades básicas, foi introduzida quando a paciente tinha 11 anos de idade. Contudo, após o diagnóstico do médico oftalmologista indicando a baixa visão, a fonoaudióloga abandonou o trabalho com a CSA, e Sabrina passou a responder à fala do outro exclusivamente por treinos de meneios de cabeça positivos e negativos, entre os 15 e os 17 anos.

\section{Investigação armada}

Exames de tomografia computadorizada indicaram atrofia cerebral na região frontoparietal esquerda. Ao repetir este exame, aos 18 anos, o resultado foi digenesia de corpo caloso. Apesar de a mãe suspeitar de comprometimento visual no olho direito desde os cinco meses de idade de Sabrina, o primeiro laudo oftalmológico foi dado aos 9 anos, a partir do exame de avaliação ortóptica, que apontou estrabismo divergente com fixação errática. Foi prescrito uso de óculos com tampão em ambos os olhos de forma alternada. Contudo, a orientação não foi seguida, pois Sabrina recusava-se a usá-lo. O segundo laudo, aos 15 anos de idade, indicou atrofia do nervo ótico, baixa de visão cortical, ceratocone, acuidade visual sob 20/400. Este resultado levou o oftalmologista a descartar o uso de óculos e orientar a família e a equipe da instituição a lidar com Sabrina da mesma forma que se fazia com indivíduos cegos ou praticamente cegos, priorizando a estimulação do tato, da audição e da localização espacial. Parece que essa orientação produziu efeitos de restrição visual nas condutas terapêuticas e pedagógicas com Sabrina, levando à retirada temporária da prancha de CSA. 


\section{Entrevistas preliminares}

Os fragmentos das entrevistas a seguir foram coletados quando a primeira autora deste estudo assumiu o caso, em junho de 2006.

A partir da pergunta da fonoaudióloga: “Em que posso ajudar?", inicialmente a queixa fonoaudiológica endereçada pela mãe foi: "a mastigação é deficiente, mas ela come de tudo". Durante a entrevista, o discurso materno retomou a história do nascimento de Sabrina e pareceu inferir que a deficiência em mastigar estaria ligada à lesão cerebral e estava satisfeita com o trabalho fonoaudiológico realizado até aquele momento, o qual permitiu a Sabrina a sucção com canudo.

No decorrer das entrevistas, a fonoaudióloga dirige uma demanda aos pais: "me digam sobre a fala de Sabrina”, à qual o pai parece responder perguntando-se: “a falaa? (silêncio)...a Sabrina se comunica mais com gestos, não é bem gestos é assim ééé, quando ela quer comer alguma coisa por exemplo ela responde éeé, é desse jeito que ela responde fazendo éée, a comunicação dela é meio confusa”. Já a mãe parece complementar a fala do pai ao referir que "a fala de Sabrina é assim ééé, geralmente a gente entende como pedido, ela só faz isso na parte da alimentação, não é assim toda hora”.

\section{Entrevistas preliminares: análise e interpretação}

A partir da pergunta da fonoaudióloga ("Em que posso ajudar?"), o discurso materno pareceu circular sobre a lesão cerebral e a função da alimentação, endereçando a demanda alimentar ao fonoaudiólogo. No que diz respeito à linguagem, não houve menção à fala de Sabrina, o que indicaria, num primeiro momento, a falta de demanda para se atuar sobre a mesma.

No entanto, no decorrer das entrevistas, parece haver sido criada a demanda de fala, conforme as passagens do discurso parental, após a fala da fonoaudióloga: "me digam sobre a fala de Sabrina”. Das questões enunciadas pelo discurso parental podemos refletir que: "mesmo que não comunique nada, o discurso representa a existência da comunicação” (LACAN, 1966/1998, p.253). Portanto, podemos inferir que a pergunta feita pela fonoaudióloga sobre a fala de Sabrina incide sobre uma questão para o pai: “a falaa?”. Assim, parece-nos que a fala da fonoaudióloga gera efeito de estranhamento na fala do pai sobre a fala de Sabrina, ou seja, mesmo que ela não fale, ela fala?

Podemos também depreender do discurso parental: "a Sabrina se comunica mais com gestos, não é bem gestos é assim éée", que a fala de Sabrina gera sobre seu pai o efeito de alienação à sanção da fala do Outro; parece que a sanção em vigor é a de tradução (de significante para significante) e assujeitamento à sanção do Outro no estrato da fala. O fato de os traços que emergem na comunicação de Sabrina não serem interpretados pelos seus pais como atos de fala, podem indicar o não reconhecimento de Sabrina como falante e ter interferido na entrada do significante. Ressalte-se que esta observação decorre nitidamente do fato de 
o modelo alçado como base para nossa análise situar-se na interlocução entre a fonoaudiologia e a psicanálise lacaniana, assentado sobre uma concepção particular de fala e linguagem.

Outro fato curioso é que o discurso parental refere-se à fala de Sabrina, reduzindo-a ao responder sem que tenha havido o perguntar. Ou melhor, o efeito de sanção da fala de Sabrina sobre a fala do pai circula sobre a alternatividade entre perguntar e responder, como na passagem: "quando ela quer comer alguma coisa, por exemplo, ela responde éeé”, sendo que esta emissão de Sabrina parece ser a transmissão da mensagem de comer feita pelo pai. Não parece haver interrogatividade na fala de Sabrina, apenas na do pai. Além disso, segundo o discurso materno, só há reconhecimento de resposta de Sabrina quando estritamente subordinada à alimentação: "ela só faz isso na parte da alimentação, não é assim toda hora".

Será que, tanto no discurso do pai quanto no da mãe, o que ocorre é que "o sujeito recebe sua mensagem do outro sob uma forma invertida..." (LACAN, 1955-56/2002, p.47), ou seja, quem só fala em comida?

E por fim, será que o "éée" de Sabrina é traço ou significante? Dizemos isso porque o significante é o que representa o sujeito para outro significante e opera por diferença, oposição e negaça. Já o traço, imprime continuidade, rasura e apagamento. Parece, à primeira vista, tratar-se de sucessão de som, sem forma, então traço e não significante. A hipótese que o pai infere sobre a fala de Sabrina ser confusa e de responder com "ééé" estaria ligada à falta de vontade de falar, e mais uma vez se aproxima da hipótese da mãe de falta de interesse. Desse modo, é possível verificar que há falta, mas de quem? E do quê? Seria falta de permissividade para o diálogo?

Sobre este questionamento (falta de permissividade para o diálogo), foi possível observar, no dia a dia de Sabrina na instituição, que a relação pai, mãe e filha parece ser sempre na ordem das demandas de fome, sede, dor, pressupondo a partir de si os desejos dela e deixando o diálogo de lado.

Diante da suposição de que faltaria diálogo, a fonoaudióloga conversou com os pais para que privilegiassem as situações de conversa com Sabrina, interpretando seus traços (movimentos corporais, expressões faciais e sucessões sonoras). Para selar esta conduta, solicitou a elaboração de um diário - a escrita, pelo cuidador, de acontecimentos envolvendo Sabrina (CASTELLANO, 2010) —, o que parece estar contribuindo para o reconhecimento do falante e a permissividade para o diálogo, pois nas palavras da mãe: "quando faço com ela o diário em casa, parece que ela relembra... pode conversar comigo... o diário... é pra família! A madrinha... chega em casa e imediatamente procura pelo diário para conversar com a Sabrina".

Embora o laudo oftalmológico salientasse o comprometimento visual, a fonoaudióloga observou que em algumas situações Sabrina colocava a mão sobre a imagem correspondente ao texto lido no diário, e em outros momentos 
demonstrava tentativas de pegar objetos. Destes acontecimentos concluiu-se que sua visão não seria impedimento para o uso da prancha de CSA.

Vejamos alguns fragmentos e análises da dialogização na cena clínica fonoaudiológica que nos permitirão tecer algumas considerações sobre como se manifestam os sintomas de linguagem de Sabrina, ou seja, apresentar o processo de avaliação diagnóstica indicativo do (re) direcionamento da terapêutica fonoaudiológica.

\section{FRAGMENTO 1}

Contexto: fonoaudióloga lê para Sabrina uma página do diário que relata viagem a São José dos Campos.

1. F.: "No domingo fui viajar para São José dos Campos com os meus pais e tios e na estrada vi muitos caminhões. Chegando lá fomos a um clube, onde vi muitos pássaros”.

2. S.: (Com padrão de tônus corporal hipotônico, coloca o dedo indicador na página esquerda do diário).

3. F.: Você gostou do passeio com os seus pais?

4. S.: (Riso, mudança de tônus corporal para o padrão espástico) é::

5. F.: "Fui no clube e lá vi muitos pássaros".

(Sabrina, 16a;6m)

A leitura do diário pela fonoaudióloga em (1) abre a cadeia metonímica e põe em curso a interação. Os efeitos dessa abertura metonímica repercutem na fala de Sabrina (2), em sua maneira de designar alguma coisa ou alguém pelo traço de colocar o dedo sobre a página em que aparecem três figuras que representariam a mãe, o pai, o caminhão e parte do texto sobre o passeio. A indeterminação do que seria a designação feita por Sabrina gera o efeito na fala da fonoaudióloga (3) de aglutinar as figuras com o texto — passeio com os pais - com o intuito de nomear e significar a fala de Sabrina numa sanção da linha da interrogatividade. Esse tipo de sanção produz efeitos em Sabrina (4) que se caracterizam, no corpo, pela graduação entre flacidez e rigidez e, na fala, pelo traço de sucessão sonora. No entanto, em (5) a fala da fonoaudióloga reintroduz a leitura do diário e a mensagem não se desenrola nem se inverte, pois nega a fala e a escrita de Sabrina que poderia vir a se tornar o reconhecimento do significante e do falante pela fala da fonoaudióloga.

\section{FRAGMENTO 2}

1. F.: (Abre o diário nas páginas que relatam sobre os acontecimentos daquela semana).

2. S.: (Coloca o dorso da mão na página do diário com figuras que relatam um churrasco).

3. F.: Você quer falar sobre o churrasco? 
4. S.: é $\rightarrow$

5. F.: O que você gostou no churrasco?

6. S.: (Coloca o dorso da mão sobre a figura de linguiças)

7. F.: Você gosta de linguiça?

8. S.: é $\rightarrow$

9. F.: Você gosta mais de carne ou de linguiça?

10. S.: (Silêncio).

11. F.: Carne?

12. S.: (Bico com os lábios).

13. F.: Linguiça.

14. S.: é $\rightarrow$

(Sabrina, 17a;11m)

Em (1) é possível observar que quem abre a interação é Sabrina ao designar a página do diário (2) que contêm figuras e relatos sobre um churrasco. Mas o problema da designação é determinar a que se refere o apontar: seria o diário? As imagens? O escrito? Para tentar minimizar a falta de nomeação que opera na fala de Sabrina, a fala da fonoaudióloga parece interpretar desde o seu próprio lugar o que Sabrina estava designando. Com isto, a fala da fonoaudióloga se volta sobre o churrasco e (3) opera numa sanção na linha da interrogatividade: "Você quer falar sobre o churrasco?”. A interrogativa incide sobre a fala de Sabrina como uma resposta afirmativa (4). Nos trechos (5), (6), (7) e (8) reaparece o mesmo tipo de sanção — a de interrogar — na fala da fonoaudióloga, e o mesmo efeito na fala de Sabrina - a designação. Já em (9), a oposição carne ou linguiça gera em (10) o silêncio de Sabrina. Por se tratar de silêncio, e silêncio implicar escuta para a própria fala e a fala do outro, a fonoaudióloga observa que esse tipo de oposição não é uma boa estratégia para que Sabrina fale, pois, para haver oposição, é preciso operar no estrato da língua, e Sabrina parece operar no estrato da escrita. Assim, a fonoaudióloga reformula o seu dizer em (11).

A pergunta da fonoaudióloga (11) gera o efeito na fala de Sabrina de marcar o traço da negação ao fazer bico com os lábios (12). Esse traço de bico com os lábios é recebido pela fonoaudióloga como sanção de negação à fala do outro e interpretado (13) como opção de Sabrina pela carne de porco, a qual é confirmada (14).

Neste último trecho do diálogo é interessante notarmos que Sabrina apresenta uma função importante da linguagem, que é negar. E, ainda, que a impossibilidade de Sabrina poder fazer a oposição, a combinação entre os significantes ou até mesmo a metáfora, estaria ligada à falta do significante; para tanto, seria preciso entrar com um novo elemento nessa terapêutica fonoaudiológica: a prancha de CSA, que daria suporte ao movimento da língua de oposição e de assunção do falante das regras da linguagem. 
Deste modo, o diário serviu para dar suporte ao diálogo, à eleição dos símbolos, à análise dos sintomas de linguagem de Sabrina e para verificar se haveria limitação de seu uso para a entrada do movimento da língua. Mas havia outro problema - a baixa visão de Sabrina. Será que ela responderia à prancha de CSA? Será que a prancha permitiria a entrada no estrato da língua?

A opção por um formato de prancha de $32 \mathrm{~cm}$ de altura por $92 \mathrm{~cm}$ de comprimento, em cujas faces internas foram coladas folhas de sulfite de cor rosa luminoso, escolhida por Sabrina, e, sobre estas, imagens retiradas da internet impressas em papel sulfite branco, recortadas em tamanho $5 \mathrm{~cm} \times 5 \mathrm{~cm}$ permitiu que os símbolos selecionados fossem dispostos de forma prática e portátil, tendo a cor favorecido a acuidade visual.

Ao utilizar a prancha de CSA, Sabrina procura lentamente a imagem com a qual se identifica e a designa ora com a mão fechada, ora com seu dorso, ou ainda com o dedo indicador. Como Sabrina estava no início da avaliação de linguagem com a CSA, pode-se observar que a iniciativa dialógica não aconteceu com a prancha como ocorreu com o diário, mas é possível observarmos, nos fragmentos a seguir, que pôde reconhecer na materialidade gráfica dos símbolos a oportunidade de dizer o que gostaria, de fazer suas escolhas.

\section{FRAGMENTO 3}

1. F.: E então, o que você quer me falar?

2. S.: (Sorri e coloca o dorso da mão sobre a imagem de uma pizza)

3. F.: Amanhã você vai comer pizza?

\section{S.: Papai::}

5. F.: Seu pai que vai te trazer!

6. S.: é::

(Sabrina, 18a;11m)

Este fragmento mostra (1) que a fala da fonoaudióloga abre a cadeia metonímica pela sanção de interrogatividade e convoca uma resposta de Sabrina. O efeito da fala da fonoaudióloga sobre a fala de Sabrina (2) foi o de designar a pizza com a conjunção de dois traços: o sorriso e a mão; cabe esclarecer que a referência à pizza foi possível pela materialidade gráfica da sua imagem. O efeito da fala de Sabrina sobre a fala da fonoaudióloga assenta-se no fato de ambas saberem que no dia seguinte haveria rodadas de pizza, na instituição, em comemoração ao dia das crianças. Assim, a fonoaudióloga assenta a pergunta (3) sobre a interpretação deste fato: “Amanhã você vai comer pizza?". A fala de Sabrina (4), ao dizer papai, permite-lhe ser reconhecida como falante, pois o efeito do uso do dêitico - amanhã — na fala da fonoaudióloga (3) imprime a marca dessa intersubjetividade e gera o efeito de combinação entre os significantes. Com 
isso, a sanção em curso na fala da fonoaudióloga também se inverte, deixa de ser interrogativa, da linha da alternância, para ser afirmativa, num movimento metonímico (5) que gera (6) outro processo na fala de Sabrina: a sucessão sonora do "ééé, com gradiente entoacional ascendente. Um fato curioso que ocorre com a fala de Sabrina é estar circunscrita ao significante da comida, pois a sua escolha foi a pizza. Mais uma vez, essa relação entre a comida e a fala se faz enigma. Mas também é o que parece ser um assunto que pode abrir o discurso de Sabrina. Vejamos a passagem abaixo:

FRAGMENTO 4

1. F.: Sabrina, o seu diário sempre conta que você toma um lanche à tarde, que tal você escolher o que quer comer hoje e contamos para os seus pais e aí quem sabe eles podem providenciar na padaria que tem aqui ao lado.

2. S.: é:: (rindo, coloca lentamente o dorso da mão sobre a imagem de uma xícara de café e depois sobre a imagem de um pastel).

(Sabrina, 18a;11m)

A fonoaudióloga (1) passa a palavra para Sabrina, ou seja, coloca-a na posição de interlocutora, abrindo a cadeia metonímica, o que lhe permite combinar dois termos (2) ao colocar a sua mão sobre as figuras de uma xícara de café e de um pastel. Este fragmento é interessante por marcar um momento em que Sabrina é o sujeito de sua própria escolha.

\section{AVALIAÇÃO DIAGNÓSTICA E DIREÇÃO DO TRATAMENTO}

Os dados extraídos ao longo das entrevistas preliminares conduziram a avaliação diagnóstica e a direção do tratamento de Sabrina ao permitir um contorno em sua constituição subjetiva, atribuindo-lhe novas posições em relação às que lhe foram atribuídas pelos pais e, ainda, ao mostrar aos pais que outra interpretação de Sabrina poderia deslocá-la para uma nova posição. O diálogo com a psicanálise foi decisivo para o manejo dessa situação, contribuindo efetivamente para a terapêutica.

Os dados da investigação anamnéstica e da investigação armada, extraídos do prontuário, delinearam o impacto do evento orgânico sobre Sabrina e indicaram medidas sobre a lida com seu corpo, seus movimentos involuntários e sua visão limitada.

A avaliação fonoaudiológica de Sabrina, assentada sobre o Modelo de Organização dos Sintomas de Linguagem, indica que os seus sintomas operam sobre o estrato da escrita (por meio do alçamento de gestos, designações ostensivas, modulações e entonações prosódicas, sucessões sonoras, na relação dialogal com o outro) e sobre o estrato da língua (por meio da resposta à demanda do outro e da prancha de CSA), sustentando a hipótese de que o problema estrutural estaria 
na ordem da fala. Em decorrência deste diagnóstico, sugere-se que a terapêutica fonoaudiológica sobre os atos de fala de Sabrina privilegie a sanção como permissividade, a sanção como posição diante da lei (lei como reconhecimento do falante, do sujeito e da linguagem) e a sanção sobre o sujeito como operação de transliteração.

\section{COMENTÁRIOS FINAIS}

Na clínica fonoaudiológica comprometida com a subjetividade e a linguagem de portadores de PC, a interação dialógica pode ser atravessada por uma fala ininteligível ou mesmo por sua falta. O sujeito dessa pesquisa inscreve-se na última situação. Nesta clínica, o fonoaudiólogo terá que se defrontar com essa fala que falta, ou seja, conceber um espaço dialogal onde circulem significantes que ressignifiquem posições para um sujeito que, ainda que pela voz de outro, fale por textos alternativos aos quais concede sua autorização. Sob essa ótica, a condição básica para a interpretação está na dependência do compromisso do fonoaudiólogo com uma escuta balizada por uma teoria psicanalítica e de linguagem que conceba o discurso como perpassado por múltiplos sentidos. A análise das transcrições das situações apresentadas mostra momentos em que Sabrina e a fonoaudióloga ultrapassam as possíveis referências dos símbolos pictográficos, entrelaçados por traços corporais e sucessões sonoras, ao tomá-los como significantes, passíveis de interpretação.

Os efeitos do uso da CSA sobre os usuários assentam-se justamente sobre a ação interpretativa que um falante exerce sobre os dizeres do outro. Em uma intervenção suportada pela ilusão de transparência da linguagem, corre-se o risco de encerrar um sentido único, aquele que é atribuído pelo interlocutor, que, ao invés de interpretar, decodifica a mensagem contida no símbolo gráfico da CSA.

O diário e a prancha de CSA podem se constituir como meios de sancionar a fala sintomática de portadores de PC ao passarem de um sistema de escrita de traços (choro, mudanças de tônus corporal, expressões faciais, designações ostensivas, silêncio) para um sistema de escrita alternativo, que possa ser interpretado pelo outro. Portanto, um manejo terapêutico que habilita esses sujeitos como falantes para que possam dialogar com o outro (CASTELLANO, 2010).

Assim, podemos concluir que, embora os portadores de PC apresentem sintomas graves no corpo e a impossibilidade de fala articulada, não estão fora do campo da fala e da linguagem, ou seja: são falantes, e seus gestos e símbolos gráficos ganham voz pela escuta e interpretação do Outro na relação dialógica instaurada na cena clínica fonoaudiológica (CASTELLANO, 2010). 


\section{REFERÊNCIAS}

CASTELLANO, G. B. (2010) "Adolescentes com paralisia cerebral: estudo de casos clínicos”, Dissertação de Mestrado, Programa de Estudos Pós-Graduados em Fonoaudiologia da Pontifícia Universidade Católica de São Paulo.

CHUN, R. Y. S. (2003) Comunicação suplementar e/ou alternativa: favorecimento da linguagem de um sujeito não falante. Pró-Fono Revista de Atualização Científica 15(1), Carapicuíba: Pró-Fono, 54-64.

DE LEMOS, C. T. G. (1995) Um percurso no interior do projeto de aquisição de linguagem. Campinas: IEL-Unicamp.

. (2002) Das vicissitudes da fala da criança e de sua investigação.

Cadernos de Estudos Linguísticos 42, Campinas: Unicamp, 41-69.

DOR, J. (1997) Estruturas e clínica psicanalítica. Rio de Janeiro: Taurus.

GOUVÊA, G. (2007) "Por uma multiestratificação estrutural dos sintomas de linguagem”. Dissertação de mestrado, Programa de Estudos Pós-Graduados em Fonoaudiologia da Pontifícia Universidade Católica de São Paulo.

GOUVÊA, G; FREIRE, R. M; DUNKER, C. (2011) Sanção em fonoaudiologia: um modelo de organização dos sintomas de linguagem. Cadernos de Estudos Linguísticos 1(53), Campinas: Unicamp, 7-25.

JAKOBSON, R. (1955/1975) "A fonologia em relação com a fonética”, in Halle M. Textos selecionados. São Paulo: Vitor Civita. (1969/2001) Linguística e Comunicação. São Paulo: Cultrix.

LACAN, J. (1955-56/2002) As psicoses. Rio de Janeiro: Jorge Zahar. (1957-58/1999) O Seminário livro 5, As formações do inconsciente. Rio de Janeiro: Jorge Zahar.

(1961-62/1996) O Seminário A Identificação. Recife/PE: Centro de Estudos Freudianos do Recife. (1964/1998) Os quatro conceitos fundamentais da psicanálise. Rio de Janeiro: Jorge Zahar. (1966/1998) Escritos. Rio de Janeiro: Jorge Zahar. (1969-70/1992) O Seminário livro 17, O avesso da psicanálise. Rio de Janeiro: Jorge Zahar. (1971-2009) O Seminário livro 18, De um discurso que não fosse semblante. Rio de Janeiro: Jorge Zahar.

SAUSSURE, F. (1916/2006) Curso de Linguística Geral. São Paulo: Cultrix.

Giuliana Bonucci Castellano giucastellano@ig.com.br 